\title{
Gangguan Psikologis dan Kesejahteraan Psikologis pada Mahasiswa Baru
}

\author{
Airin Triwahyuni, Clement Eko Prasetio \\ Program Studi Psikologi, Fakultas Psikologi, Universitas Padjadjaran, Bandung
}

Abstrak. Mahasiswa baru memiliki kerentanan mengalami gangguan psikologis. Kesejahteraan psikologis diketahui merupakan sumber daya bagi mahasiswa baru dalam menghadapi tantangan perkuliahan. Namun, demikian, studi yang mengidentifikasi dimensi-dimensi kesejahteraan psikologis sebagai faktor protektif mahasiswa baru masih jarang dilakukan. Penelitian ini menggunakan metode regresi sederhana untuk mengetahui hubungan indikasi gangguan psikologis dengan kesejahteraan psikologis secara umum dan stepwise multiple regression untuk mengidentifikasi dimensi kesejahteraan psikologis yang signifikan menjadi prediktor indikasi gangguan psikologis. Partisipan penelitian ini berjumlah 151 mahasiswa baru di Fakultas Psikologi Universitas "X", Jawa Barat. Alat ukur penelitian ini adalah kesejahteraan psikologis dari Ryff dan Self Report Questionnaire (SRQ-20). Hasil menunjukkan bahwa kesejahteraan psikologis secara umum dapat menjadi faktor protektif dan secara spesifik, dimensi penerimaan diri dan penguasaan lingkungan merupakan faktor protektif terhadap indikasi gangguan mental pada mahasiswa baru.

Kata Kunci: gangguan psikologis, kesejahteraan psikologis, mahasiswa baru

\section{Psychological Disorder and Psychological Well-Being among First-year University Students}

Abstract. First-year university students are vulnerable to certain psychological disorders. Psychological Well-Being (PWB) is one of the resources they can use to face academic challenges. However, research focusing to identify PWB as protective factor among first-year university students is still rare. This study employs quantitative method involving 151 respondents from the Faculty of Psychology of University X in West Java. It uses a PWB scale composed by Ryff and Self Report Questionnaire (SRQ-20). It also employs simple multiple regression to determine the relation between PWB and symptoms of psychological disorders, on one hand, and stepwise multiple regression to find out which dimensions of PWB are significant to anticipate psychological disorder, on the other. This study argues that PWB, especially self-acceptance and environment mastery dimension, can be used as a protective factor against psychological disorders.

Keywords: first-year university students, psychological disorders, psychological well-being

Korespondensi: Airin Triwahyuni. Email: airin.triwahyuni@unpad.ac.id 
Hasil riset terdahulu menunjukkan adanya peningkatan pada permasalahan gangguan psikologis pada mahasiswa pada kurun waktu terakhir (Storrie et al., 2010). Mahasiswa adalah kelompok yang rentan terhadap gangguan psikologis (Bruffaerts et al., 2018; Saleem \& Mahmood, 2013). Mahasiswa berpotensi mengalami berbagai gangguan psikologis mulai dari ringan sampai dengan berat. Sebuah penelitian menyebutkan prevalensi mahasiswa mengalami gangguan psikologis sebesar $48 \%$ untuk gangguan psikologis ringan dan $10 \%$ untuk gangguan psikologis berat (Shiels et al., 2008). Gangguan psikologis ringan misalnya rasa cemas berlebihan, sulit tidur, gelisah, perubahan suasana hati, dan perubahan pola makan. Gangguan berat yang telah memenuhi kriteria diagnosis gangguan psikologis misalnya depresi, gangguan belajar, percobaan bunuh diri, perilaku melukai diri sendiri, gangguan makan, dan penyalahgunaan obat (Gallagher et al., 2000). Penelitian lainnya menyebutkan bahwa dalam 13 tahun terakhir terjadi peningkatan jumlah mahasiswa yang mengalami depresi sebanyak dua kali lipat dan tiga kali lipat pada perilaku bunuh diri (Yasin \& Dzulkifli, 2010). Pada mahasiswa baru ditemukan prevalensi yang lebih tinggi yaitu satu dari tiga orang mengalami salah satu dari gangguan berat seperti gangguan cemas, gangguan afektif, atau gangguan penyalahgunaan obat (Auerbach et al., 2018).
Gangguan psikologis yang dialami mahasiswa dapat berdampak pada berbagai aspek dalam kehidupan perkuliahan. Pada level individu, gangguan psikologis dapat mempengaruhi kondisi fisik, emosional, kemampuan berpikir, dan keberfungsiannya dalam lingkungan sosial (Agnafors et al, 2020; VanderLind, 2017). Misalnya, depresi dapat membuat seorang mahasiswa mengalami perubahan afektif yang mengganggu aktivitas sehari-hari, kehilangan minat untuk melakukan aktivitas sehari-hari termasuk aktivitas belajar, kemampuan memusatkan perhatian menjadi terganggu, kemampuan mengingat terganggu, sulit mengambil keputusan, kehilangan motivasi, merasa tidak berharga, menjauhkan diri dari lingkungan sosial, dan pada beberapa kasus melakukan percobaan bunuh diri (American Psychiatric Association, 2013). Individu yang mengalami gangguan psikologis berat biasanya mengalami kesulitan untuk memproses informasi yang merupakan hal penting dalam keberhasilan di bidang akademis (Angelidis et al., 2019; Yousefi et al., 2016). Studi lain menunjukkan bahwa mahasiswa yang mengalami gangguan psikologis beresiko untuk tidak melanjutkan studinya (dropout) (Hjorth et al., 2016). Selain itu, mahasiswa yang mengalami gangguan psikologis juga berpotensi mempengaruhi orang-orang di sekelilingnya karena dapat melakukan perilaku yang membahayakan dirinya dan orang lain (Kitzrow, 2009). 
Munculnya gangguan psikologis pada mahasiswa baru sangat erat kaitannya dengan dunia perkuliahan yang baru saja mahasiswa masuki. Pada saat seorang mahasiswa baru memasuki dunia perkuliahan, mahasiswa menghadapi banyak perubahan. Memasuki dunia perkuliahan adalah salah satu masa transisi dalam kehidupan (Bowman, 2010). Beberapa penelitian menyatakan bahwa tingkat stres meningkat saat seseorang menjadi mahasiswa (Holmes \& Silvestri, 2016; Pascoe et al., 2020; Roberts et al., 2000; Saleh et al., 2017; Stewartbrown et al., 2000). Mahasiswa juga dikatakan memiliki tingkat stres yang lebih tinggi dibandingkan dengan populasi non-mahasiswa (Adlaf et al., 2010). Lingkungan yang berbeda dengan sebelumnya, jauh dari orang tua, dan tuntutan akademik merupakan sumber stress bagi mahasiswa baru (Jackson et al, 2013; Saleh et al., 2017). Beberapa area kehidupan mahasiswa seperti keberhasilan akademik, relasi dengan teman dan keluarga, keuangan, dan kesehatan tubuh menjadi salah satu sumber kehawatiran pada mahasiswa (Beiter et al., 2015). Pada periode memasuki perkuliahan ini banyak mahasiswa mengalami onset pertama gejala gangguan psikologis (Pedrelli et al., 2015). Mahasiswa baru yang dapat secara efektif beradaptasi dengan lingkungan akademis dan sosial yang baru di dunia perkuliahan memiliki peluang lebih besar untuk dapat mengikuti pendidikan di universitas dan menyelesaikan pendidikannya (van Rooij et al, 2018).
Berbagai usaha untuk mengurangi dampak gangguan psikologis pada mahasiswa telah dilakukan, misalnya dengan konseling. Mahasiswa yang mengikuti konseling mengatakan bahwa konseling membantu mereka untuk mencapai tujuan mereka di universitas dan membantu mereka mengurangi stress yang berpotensi mengganggu penyelesaian tugas-tugas akademis (Kitzrow, 2009). Konseling pada mahasiswa yang mengalami gangguan psikologis juga terbukti dapat berdampak positif pada nilai akademik dibandingkan mahasiswa yang tidak mendapat konseling (Schwitzer et al, 2018). Meskipun demikian mengatasi masalah gangguan psikologis pada mahasiswa bukan hanya menjadi tanggung jawab profesional yang bekerja di institusi pendidikan namun juga menjadi tanggung jawab semua pihak, termasuk juga institusi pendidikan yang membuat kebijakan (Baik et al., 2019). Universitas dapat berperan misalnya dalam membantu memberikan dukungan dan sumber daya bagi mahasiswa baru dalam menghadapi tekanan selama transisi menjalani kehidupan perkuliahan (Aldiabat et al., 2014). Bantuan profesional hanya dapat berdampak pada sebagian kecil populasi mahasiswa yang telah mengalami gangguan psikologi karena pada umumnya bantuan profesional bersifat kuratif. Pada sisi lain, terdapat keterbatasan karena tidak seimbangnya jumlah konselor dengan mahasiswa yang membutuhkan penanganan konseling (Auerbach et al, 2016; Xiao et al, 
2017). Pendekatan yang bersifat preventif pada mahasiswa juga perlu dilakukan karena dapat mengurangi jumlah penderita gangguan mental dalam jangka panjang (Huppert, 2009). Universitas sebagai institusi pendidikan perlu memperhatikan kesejahteraan mahasiswa secara personal bukan hanya mempersiapkan mahasiswa agar menjadi pekerja profesional yang sukses (Kumaraswamy, 2013; Sreeramareddy et al., 2007).

Saat ini sedang berkembang salah satu pendekatan ilmiah yang memfokuskan pada cara-cara yang membuat seseorang berkembang, memfokuskan pada kekuatan dalam diri manusia, bukan pada kelemahan pada diri manusia yaitu pendekatan kesejahteraan secara psikologis (well being). Pemahaman mendalam mengenai kesejahteraan psikologis pada perilaku, kondisi biologis, dan perilaku sosial dapat berdampak secara positif bagi individu, organisasi, dan masyarakat secara umum (Huppert, 2009; Ryff, 2018). Pendekatan ini tidak memfokuskan pada kelompok yang telah mengalami gangguan mental namun lebih memfokuskan pada kelompok yang tidak mengalami gangguan mental yaitu pada individu secara umum. Sebuah penelitian epidemiologis membuktikan bahwa pendekatan kuratif pada kelompok yang telah mengalami gangguan mental tidak akan mengurangi jumlah gangguan mental karena akan selalu ada penambahan jumlah individu yang mengalami gangguan mental (Rose et al., 2008). Oleh karena itu, studi yang berfokus pada pendekatan kesejahteraan psikologis berkaitan dengan gejala gangguan psikologis menjadi penting.

Kesejahteraan psikologis (psychological well-being/PWB) adalah pemaknaan seseorang bahwa ia telah mencapai hakikatnya yang terbaik sebagai manusia (Ryff, 2014). Seorang manusia pada hakikatnya adalah makhluk yang tidak hanya berusaha untuk mendapatkan kesenangan, dan terpuaskan secara biologis namun berusaha mencari makna hidupnya dengan mengoptimalkan potensi yang ada di dalam dirinya. Kondisi well-being ini terlihat dari pemahaman dan penerimaan seseorang terhadap kekuatan dan kelemahan dirinya, memiliki tujuan hidup, memiliki keinginan untuk terus mengembangkan diri, relasi yang positif dengan orang lain, tidak bergantung pada orang lain, dan mampu mengatasi berbagai macam kesulitan dalam hidupnya. Ryff (1989) memformulasikan sebuah model teoretis mengenai kesejahteraan psikologis yang mencakup karakteristik dan persepsi yang luas mengenai keberfungsian sebagai individu yaitu autonomy, environmental mastery, personal growth, positive relation with others, purpose in life, dan self-acceptance.

Dalam berbagai penelitian, kesejahteraan psikologis ditemukan memiliki hubungan dengan kondisi kesehatan (Ryff \& Singer, 2008). Penelitian pada mahasiswa di Jepang menemukan bahwa profil kesejahteraan psikologis berhubungan dengan tingkat depresi dan kecemasan (Liu et al, 2009). Namun di sisi 
lain, berhubungan dengan kepuasan hidup dan emosi positive (Bowman, 2010). Kesejahteraan psikologis merupakan faktor pelindung pada proses adaptasi awal perkuliahan (Angela et al,, 2008; Hurtado \& Carter, 1997; Mendoza-denton et al., 2014). Salah satu potensi sumber daya yang dapat membuat mahasiswa berhasil beradaptasi dengan lingkungan perkuliahan yang baru adalah kesejahteraan psikologis (Bowman, 2010). Stres akademik yang dialami mahasiswa ternyata juga berhubungan dengan kondisi kesejahteraan psikologis mahasiswa tersebut (Chow, 2007). Penelitian sebelumnya menunjukkan bahwa kesejahteraan psikologis berkorelasi signifikan dengan pengontrolan terhadap simtom depresi, dan dapat membantu pemulihan kesehatan mental bagi orang dengan gangguan psikologis (Browne et al, 2017). Mahasiswa dengan kesejahteraan psikologis yang tinggi, cenderung menggunakan tiga strategi penyelesaian masalah yaitu pemaknaan secara positif, mencari dukungan, dan perencanaan (Freire et al., 2016). Mahasiswa dapat mengelola kondisi kesejahteraan psikologisnya melalui penggunaan pelayanan konseling dan behavioral intervention yang disediakan oleh universitas (Cooke et al, 2006; Mahomed et al., 2019; Weiss et al., 2016). Pemahaman yang komprehensif mengenai kesejahteraan psikologis pada masa awal perkuliahan dapat mempermudah pembuatan intervensi yang dapat membantu mahasiswa melalui masa transisi dari sekolah ke universitas (Bewick et al., 2010).
Kesejahteraan psikologis sebagai faktor protektif gangguan psikologis dapat dijelaskan melalui penelitian di area sistem saraf. Pada penelitian menggunakan resonansi magnetik yang bertujuan untuk menemukan perbedaan individu dalam merespon stimulus negatif ditemukan bahwa terjadi peningkatan aktivasi amigdala bagian kiri dan kanan. Perbedaan tingkat aktivasi amigdala ini berhubungan dengan profil kesejahteraan psikologis individu tersebut. Individu dengan tingkat kesejahteraan tinggi cenderung lebih lambat mengevaluasi informasi negatif, menujukkan penurunan aktivasi amigdala, dan peningkatan aktivasi ventral anterior cingulated cortex (Suardi et al, 2016; Tang etal, 2019; Van Reekum etal, 2007). Penelitian lain menunjukkan bahwa tingkat kesejahteraan psikologis yang tinggi berhubungan dengan volume insular cortex. Terdapat hubungan positif antara pengembangan diri, relasi positif dengan orang lain, dan tujuan hidup dengan grey matter pada insular cortex sebelah kanan (Lewis et al., 2013).

Di Indonesia sendiri belum banyak penelitian yang mengenai gangguan psikologis pada mahasiswa, padahal lima tahun belakangan ini cukup banyak media massa yang melaporkan mahasiswa yang mengalami gangguan psikologis berat. Pada umumnya penelitian mengenai gangguan psikologis di Indonesia masih berfokus pada prevalensi dan penyebabnya. Sebuah penelitian pada mahasiswa universitas di Jakarta pada tahun 2017 menunjukkan sebanyak 
$12.69 \%$ mahasiswa mengalami gangguan psikologis. Data ini menunjukan tingkat yang lebih tinggi dua kali lipat jika dibandingkan dengan riset kesehatan dasar 2013 yaitu sebesar 6\% (Vidiawati et al, 2017). Penelitian lainnya pada mahasiswa kedokteran berfokus pada jenis gangguan psikologis yang dialami dan stressorstressor diduga menjadi pemicu (Sari et al., 2017). Terdapat sebuah penelitian yang mengaitkan kesejahteraan psikologis dengan tingkat stres pada mahasiswa yang sedang menyelesaikan tugas akhir (Aulia \& Panjaitan, 2019). Namun demikian, penelitian tersebut belum memberikan gambaran mengenai dimensi-dimensi pada kesejahteraan psikologis yang berperan dalam menurunkan gejala gangguan psikologis. Adanya analisis dimensi kesejahteraan psikologis tersebut dapat membantu memberikan saran yang lebih spesifik untuk menyelesaikan permasalahan yang terjadi. Salah satu penelitian mengenai warga Indonesia yang berkuliah di United Kingdom (UK) menunjukan profil kesejahteraan psikologis yang spesifik sehingga dapat memberikan rekomendasi intervensi berdasarkan profil kesejahteraan psikologis responden, misalnya merekomendasikan untuk memperkuat organisasi mahasiswa Indonesia yang ada di UK dan membuat aktivitas-aktivitas yang dapat meningkatkan hubungan antara mahasiswa Indonesia dan mahasiswa internasional berdasarkan profil dimensi environmental mastery yang rendah (Susanti \& Supradaniati, 2018).
Berdasarkan penelitian-penelitian sebelumnya mengenai gangguan psikologis pada mahasiswa dan kesejahteraan psikologi, penelitian ini bertujuan untuk mendapatkan gambaran mengenai hubungan antara gangguan psikologis dengan kesejahteraan psikologis dan menganalisis dimensi kesejahteraan psikologis yang dapat menjadi faktor protektif bagi mahasiswa agar terhindar dari gangguan psikologis.

\section{Metode}

Pendekatan yang digunakan dalam penelitian ini adalah pendekatan kuantitatif. Seluruh mahasiswa fakultas Psikologi Universitas "X" Bandung angkatan 2017, semester 2 , berjumlah 154 orang menjadi target populasi penelitian ini. Teknik non-random sampling yaitu dengan mengambil keseluruhan populasi mahasiswa baru dilakukan karena peneliti menemukan banyak mahasiswa baru yang menunjukan gejala gangguan mental emosional. Pengambilan data dilakukan pada Mei 2018 selama dua minggu. Prosedur pengambilan datanya adalah dengan menyebarkan kuesioner kepada responden dan meminta mereka untuk mengisi. Sebanyak 151 orang mahasiswa bersedia menjadi partisipan penelitian, dan 3 mahasiswa yang lain tidak bersedia.

\section{Analisis data}

Variabel dalam penelitian ini terdiri dari indikasi gangguan mental dan kesejahteraan psikologis. (1) Gangguan psikologis didefinisikan sebagai kondisi yang 
mengindikasikan bahwa individu mengalami suatu perubahan emosional yang mungkin berkembang menjadi keadaan yang patologis dan dapat membahayakan bagi kesehatan jiwa individu. Gangguan psikologis dalam penelitian ini diukur melalui Self Report Questionnaire (SRQ-20) dari World Health Organization (1994), yang terdiri dari 20 butir pertanyaan. Setiap butir pertanyaan memiliki dua pilihan jawaban, yaitu "ya" dan "tidak". Jawaban "ya" diskor 1, sedangkan jawaban "tidak" diskor 0 . Individu yang mendapat total skor $\geq 6$ dikategorikan sebagai individu yang diindikasikan mengalami gangguan psikologis (gangguan neurotik) dan disarankan untuk bertemu dengan psikolog atau tenaga kesehatan jiwa lain. Alat ukur SRQ-20 diterjemahkan oleh tim dari Pusat Studi Psikometri, Asesmen dan Evaluasi Program Fakultas Psikologi Universitas Padjadjaran. Hasil perhitungan reliabilitas menggunakan Alpha Cronbach didapatkan koefisien reliabilitas sebesar .796 dan pengumpulan bukti validitas menggunakan confirmatory factor analysis menunjukkan bahwa SRQ-20 telah memenuhi kriteria model fit (Angela et al., 2008). (2) Kesejahteraan psikologis diukur menggunakan alat ukur PWB dari Ryff (1995). Alat ukur ini terdiri 42 butir pernyataan yang mengukur enam dimensi yaitu self-acceptance, purpose in life, personal growth, positive relation with others, autonomy, dan environmental mastery. Setiap dimensi diukur melalui tujuh pernyataan dengan enam pilihan jawaban yang berupa
Sangat Tidak Setuju, Tidak Setuju, Agak Tidak Setuju, Agak Setuju, Setuju, Sangat Setuju. Hasil perhitungan reliabilitas menggunakan Alpha Cronbach didapatkan koefisien reliabilitas sebesar .933. Hasil reliabilitas per dimensi adalah sebagai berikut dimensi autonomy (á = .701), dimensi environmental mastery (á = .789), dimensi personal growth (á = .666), dimensi positive relation with others (á=0.809), dimensi purpose in life (á = .807), dan dimensi self-acceptance (á = .815). Pengumpulan bukti validitas menggunakan confirmatory factor analysis menunjukkan bahwa PWB Scale memenuhi kriteria model fit $\left(X^{2}=1289.88 ; p=\right.$ $.00, \mathrm{RMSEA}=.072, \mathrm{CFI}=.95, \mathrm{SRMR}=.076)$. Ada dua item pada kuesioner PWB yang tidak digunakan, karena memiliki nilai $t$-values yang tidak signifikan, yaitu butir 9 (dimensi personal growth) dan butir 37 (dimensi autonomy).

Analisis statistik dilakukan melalui dua langkah yaitu (1) Simple multiple regression untuk mengetahui hubungan gangguan mental emosional dengan skor PWB secara umum, (2) Multiple linear regression dengan metode enter untuk mengetahui hubungan gangguan psikologis dengan keseluruhan dimensi PWB, (3) Stepwise multiple regression digunakan untuk mencari tahu dimensi-dimensi kesejahteraan psikologis yang signifikan menjadi prediktor bagi gangguan psikologis. Analisis statistikini digunakan karena analisis ini dapat mengetahui dimensi yang paling signifikan menjadi prediktor bagi variabel dependen. Penghitungan statistic menggunakan SPSS for Windows ver.23. 


\section{Hasil}

Penelitian ini bertujuan untuk mendapatkan gambaran mengenai hubungan antara gangguan psikologis dengan kesejahteraan psikologis dan menganalisis dimensi kesejahteraan psikologis yang dapat menjadi faktor protektif bagi mahasiswa agar terhindar dari gangguan psikologis. Peneliti melibatkan 151 (96.7\%) mahasiswa bersedia menjadi partisipan penelitian. Sejumlah 121 orang adalah perempuan dan 30 orang adalah laki-laki. Rentang usia partisipan adalah 1720 tahun dengan sebagian besar berada pada usia 18 tahun (52\%) dan 19 tahun (41\%).

Tabel 1

Statistik Deskriptif Gangguan Psikologis dan Dimensi PWB

\begin{tabular}{lcc}
\hline \multicolumn{1}{c}{ Variabel } & $n$ & $M(S D)$ \\
\hline Gangguan Psikologis & 151 & $8.64(4.19)$ \\
Menjawab "Ya" $\geq 6$ dari 20 & 114 & $10.37(3.22)$ \\
Menjawab "Ya" $<6$ dari 20 & 37 & $3.35(1.51)$ \\
Psychological Well-Being & 151 & $166.38(25.16)$ \\
Autonomy & 151 & $24.38(4.75)$ \\
Environmental Mastery & 151 & $26.75(5.18)$ \\
Personal Growth & 151 & $31.09(4.50)$ \\
Positive Relation with Others & 151 & $30.01(5.78)$ \\
Purpose in LIfe & 151 & $29.44(5.77)$ \\
Self-acceptance & 151 & $24.66(5.60)$ \\
\hline
\end{tabular}

Tabel 1 menunjukkan rata-rata dari indikasi gangguan psikologis dan kesejahteraan psikologis, pada mahasiswa baru, yakni mahasiswa jenjang sarjana angkatan 2017. Pada indikasi gangguan psikologis, ada sekitar 114 mahasiswa (75.5\%) yang menjawab "Ya” lebih/sama dengan enam, hal ini berarti mereka diindikasikan mengalami gangguan psikologis sehingga disarankan untuk menghubungi tenaga kesehatan mental. Sedangkan ada, 31 mahasiswa (24.5\%) yang menjawab "Ya" kurang dari enam, hal ini berarti mereka tidak diindikasikan mengalami gangguan psikologis. Pada variable kesejahteraan psikologis, ratarata dimensi cukup bervariasi dari (24.3831.09). Rata-rata dimensi kesejahteraan psikologis yang paling tinggi adalah personal growth $(M=$ $31.09, S D=4.50$ ) dan yang paling rendah adalah dimensi autonomy $(M=24.38, S D=4.75)$. 


\section{Tabel 2}

Interkorelasi antar Variabel-variabel

\begin{tabular}{lccccccr}
\hline \multicolumn{1}{c}{ Variabel } & 1 & 2 & 3 & 4 & 5 & 6 & 7 \\
\hline 1. Indikasi gangguan mental & - & & & & & & \\
2. Psychological Well-Being & $-.552^{* *}$ & - & & & & & \\
3. Autonomy & $-.307^{* *}$ & $.598^{* *}$ & - & & & & \\
4. Environmental Mastery & $-.510^{* *}$ & $.838^{* *}$ & $.406^{* *}$ & - & & & \\
5. Personal Growth & $-.401^{* *}$ & $.793^{* *}$ & $.335^{* *}$ & $.603^{* *}$ & - & & \\
6. Positive Relation with Others & $-.403^{* *}$ & $.744^{* *}$ & $.324^{* *}$ & $.630^{* *}$ & $.567^{* *}$ & - & \\
7. Purpose in LIfe & $-.417^{* *}$ & $.815^{* *}$ & $.404^{* *}$ & $.650^{* *}$ & $.651^{* *}$ & $.468^{* *}$ & - \\
8. Self-acceptance & $-.522^{* *}$ & $.794^{* *}$ & $.418^{* *}$ & $.642^{* *}$ & $.580^{* *}$ & $.517^{* *}$ & $.601^{*}$ \\
\hline Catatan & & & & & & &
\end{tabular}
Catatan. ${ }^{* *} \mathrm{p}<.01$.

Tabel 2 menunjukkan interkorelasi antarvariabel yang ada, dapat dilihat bahwa terdapat hubungan negatif dan signifikan antar variabel gangguan mental emosional dengan kesejahteraan psikologis beserta dimensi-dimensi kesejahteraan psikologis. Artinya, semakin rendah skor total kesejahteraan psikologis, maka semakin banyak gejala gangguan mental emosional pada mahasiswa. Begitu juga sebaliknya, semakin tinggi skor total kesejahteraan psikologis, maka semakin sedikit gejala gangguan mental emosional pada mahasiswa. 
Tabel 3

Penjelasan Singkat Uji Asumsi

\begin{tabular}{|c|c|c|}
\hline Uji Asumsi & Penjelasan singkat & $\begin{array}{c}\text { Teknik Statistik yang } \\
\text { digunakan }\end{array}$ \\
\hline Uji Normalitas & $\begin{array}{l}\text { Sebuah uji untuk mengetahui bentuk } \\
\text { penyebaran suatu data yang } \\
\text { berkorespondensi pada distribusi normal. }\end{array}$ & Uji Kolmogorov-Smirnov \\
\hline $\begin{array}{l}\text { Uji } \\
\text { Multikolinearitas }\end{array}$ & $\begin{array}{l}\text { Sebuah uji untuk mengetahui korelasi antar } \\
\text { variabel bebas (independent variable) pada } \\
\text { uji regresi berganda. } \\
\text { Diharapkan korelasi antar variabel } \\
\text { independent rendah dan korelasi variabel } \\
\text { independent dengan dependent tinggi. }\end{array}$ & $\begin{array}{l}\text { Nilai VIF atau Tolerance pada } \\
\text { uji regresi }\end{array}$ \\
\hline Uji Linearitas & $\begin{array}{l}\text { Sebuah uji untuk mengetahui ada atau } \\
\text { tidaknya hubungan linear antar variabel. } \\
\text { Sebab hubungan regresi hanya akan bisa } \\
\text { tepat, jika terdapat hubungan linear antar } \\
\text { variabel dependen dan independent }\end{array}$ & Uji Linearitas \\
\hline $\begin{array}{l}\text { Uji } \\
\text { Homoskedasitisitas }\end{array}$ & $\begin{array}{l}\text { Sebuah uji yang memeriksa penyebaran } \\
\text { variansi dari data variabel dependen pada } \\
\text { rentang variabel independent. } \\
\text { Hal yang diharapkan adalah penyebaran } \\
\text { variansi data variabel dependent sama } \\
\text { semua pada rentang variabel independent }\end{array}$ & $\begin{array}{l}\text { Melihat penyebaran pada } \\
\text { scatter plot. }\end{array}$ \\
\hline
\end{tabular}

Catatan. Sumber penjelasan singkat dari "Multivariate Data Analysis" ditulis oleh Hair, J. F., Tatham, R. L., Anderson, R. E., dan Black, W. C., 2019, 5.

Setelah dilakukan analisis korelasi antar variabel dan melakukan beberapa uji asumsi regresi, seperti uji normalitas, multikolinearitas, linearitas, dan homoskedastisitas, hasilnya adalah data bersifat normal, tidak ditemukan multikolinearitas, data antarvariabel bersifat linear, dan ditemukan homoskedasitias pada data. Maka peneliti melakukan analisis selanjutnya yakni regresi berganda. Penjelasan lebih detail mengenai uji asumsi ada pada Tabel 3.

Teknik regresi yang digunakan adalah stepwise multiple regression. Sebelum melakukan teknik regresi itu, penulis melakukan regresi linear sederhana, untuk memastikan bahwa kesejahteraan psikologis dapat memprediksi gangguan psikologis. Tabel 4 menunjukkan hasil regresi linear sederhana dengan variabel prediktor adalah kesejahteraan psikologis terhadap variabel gangguan psikologis. Didapatkan bahwa kesejahteraan psikologis dapat secara signifikan dapat menjadi prediktor bagi gangguan psikologis $\left(R^{2}\right.$ $=.315 ; F(1,149)=68.422 ; p=.000 ; 95 \% \mathrm{CI}$ [.126, -.077]). Jika dilihat dari nilai regresi $\left(\mathrm{R}^{2}\right)$ PWB dapat menjelaskan $31.5 \%$ varian dari gangguan psikologis. 


\section{Tabel 4}

Simple Linear Regression dari PWB terhadap Gangguan Mental Emosional

\begin{tabular}{cccccc}
\hline Variable & $\beta$ & $S E$ & $t$ & $p$ & $95 \%$ CI \\
\hline PWB * SRQ & -.101 & .012 & -8.272 & .000 & {$[-.126,-.077]$}
\end{tabular}

Catatan. $\mathrm{PWB}=$ psychological well-being; $\mathrm{SRQ}$ = self-report questionnaire; $\mathrm{CI}$ = confidence interval.

Teknik multiple linear regression dengan metode enter dilakukan antara dimensi-dimensi pada kesejahteraan psikologis, yaitu selfacceptance, autonomy, positive relations with others, purpose in life, personal growth, environmental mastery (sebagai variabel independen) dengan gangguan psikologis (sebagai variabel dependen). Berikut ini hasilnya:

\section{Tabel 5}

Multiple Linear Regression Dimensi PWB terhadap Gangguan Psikologis

\begin{tabular}{lcccc}
\hline \multicolumn{1}{c}{ Variabel } & $\beta$ & $S E$ & $t$ & $p$ \\
\hline Autonomy & -.053 & .076 & -.708 & .480 \\
Environmental mastery & -.179 & .105 & -1.703 & .091 \\
Personal growth & -.053 & .106 & -.496 & .620 \\
Positive relations & -.059 & .077 & -.766 & .445 \\
Purpose in life & -.024 & .084 & -.284 & .777 \\
Self-acceptance & -.214 & .085 & -2.515 & $.013^{*}$ \\
\hline
\end{tabular}

Catatan. ${ }^{*} \mathrm{p}<.05$.

Tabel 6 menunjukkan hasil multiple linear regression dengan variabel prediktor adalah dimensi-dimensi PWB terhadap variabel gangguan psikologis. Didapatkan bahwa secara keseluruhan dimensi PWB secara signifikan dapat menjelaskan gangguan psikologis sebesar 33\% $\operatorname{varian}\left(R^{2}=.330 ; F(6,144)=11.826 ; p=.000\right)$.
Setelah itu, stepwise multiple regression dilakukan untuk mengetahui dimensi PWB yang paling signifikan dan paling dapat menjadi prediktor pada gangguan psikologis. Pada teknik ini variabel independen adalah seluruh dimensi PWB dan variabel dependen adalah gangguan psikologis. Berikut ini hasilnya:

\section{Tabel 6}

Stepwise Multiple Regression dari Dimensi-Dimensi Psychological Well-Being terhadap Gangguan Psikologis

\begin{tabular}{|c|c|c|c|c|c|c|c|}
\hline \multirow{2}{*}{ Variable } & \multirow{2}{*}{$\mathrm{B}$} & \multicolumn{2}{|c|}{$95 \% \mathrm{CI}$ for $\mathrm{B}$} & \multirow{2}{*}{ SE B } & \multirow{2}{*}{$\beta$} & \multirow{2}{*}{$\mathrm{R}^{2}$} & \multirow{2}{*}{$\Delta \mathrm{R}^{2}$} \\
\hline & & LL & UL & & & & \\
\hline Model 1 & & & & & & .276 & $.276^{* *}$ \\
\hline Self-acceptance & -.427 & -.539 & -.315 & .057 & -.525 & & \\
\hline Model 2 & & & & & & .321 & $.045^{* *}$ \\
\hline Self-acceptance & -.260 & -.411 & -.109 & .076 & -.320 & & \\
\hline Environmental Mastery & -.260 & -.423 & -.096 & .083 & -.296 & & \\
\hline
\end{tabular}


Berdasarkan tabel 6 didapatkan bahwa hanya dimensi self-acceptance dan environmental mastery signifikan menjadi prediktor bagi gangguan psikologis. Selfacceptance menjadi dimensi yang paling kuat memprediksi gangguan psikologis. Hal ini dapat dilihat pada nilai regresinya, bahwa selfacceptance dapat memprediksi $27.6 \%$ dari varians gangguan mental emosional. Lalu pada model 2, environmental mastery - bersama dengan self-acceptance - juga bisa menjadi prediktor yang signifikan bagi gangguan mental emosional, yakni 32.1\% varians dari gangguan mental emosional dapat diprediksi oleh self-acceptance dan environmental mastery. Model 2 menjadi model akhir yang paling tepat untuk memprediksi jumlah gejala yang mengindikasikan gangguan psikologis. Dimensi PWB yang lain, tidak menjadi prediktor yang signifikan bagi gangguan mental emosional. Effect size self-acceptance dan environmental mastery tergolong besar, yakni Cohen's d $=.452$.

\section{Pembahasan}

Penelitian ini menggambarkan hubungan antara indikasi gangguan psikologis dengan kesejahteraan psikologis pada mahasiswa baru. Indikasi seorang mahasiswa baru mengalami gangguan psikologis dapat diprediksi melalui tingkat kesejahteraan psikologis secara umum dan secara spesifik melalui bagaimana mahasiswa baru tersebut menerima diri apa adanya dan bagaimana mahasiswa tersebut merasa nyaman dan memiliki kendali pada lingkungan baru dimana mahasiswa berada.

Seorang mahasiswa baru yang memiliki kesejahteraan psikologis rendah akan cenderung lebih rentan mengalami gejala-gejala gangguan mental, seperti selalu merasa cemas / tegang/khawatir, kehilangan rasa diri berharga, penurunan kemampuan kognisi, penurunan energi, dan munculnya gejala fisik yang disebabkan oleh permasalahan psikologis pada masa satu tahun pertama menjadi mahasiswa. Sedangkan mahasiswa baru yang mampu memiliki hubungan antar pribadi yang bermakna, memiliki kendali dan merasa nyaman di lingkungan dimana mahasiswa berada dan menyadari potensinya untuk berkembang lebih jarang menunjukan gejalagejala gangguan mental pada masa tahun pertamanya berkuliah. Mahasiswa baru yang memiliki kesejahteraan psikologis tinggi cenderung lebih dapat mengatasi hambatan yang mahasiswa temui (Freire et al., 2019; Zajacova et al., 2005). Mahasiswa juga cenderung lebih fleksibel, resilien, efisien dalam menyelesaikan masalah, dan lebih berkomitmen untuk mencapai keberhasilan daripada memfokuskan diri untuk menghindari kegagalan (Freire et al, 2019; Schunk \& Pajares, 2002).

Secara spesifik, penelitian ini mengindikasikan bahwa bagaimana seseorang mahasiswa baru dapat memaknakan dirinya secara positif di dunia perkuliahan yang baru menentukan bagaimana mahasiswa dapat 
terhindar dari kemungkinan mengalami gangguan mental. Mahasiswa baru berpeluang untuk mengalami hal-hal yang kurang menyenangkan pada masa satu tahun pertama karena perbedaan tuntutan perkuliahan, harus mencari teman baru, dan beberapa jauh dari orang tua sehingga harus belajar hidup lebih mandiri. Namun, mahasiswa yang tetap dapat memaknakan dirinya secara positif meskipun mengalami berbagai kesulitan maka mahasiswa akan dapat terhindar dari kemungkinannya mengalami gangguan psikologis. Seorang mahasiswa yang memaknakan diri secara negatif, misalnya merasa ada yang salah dengan dirinya akibat pengalaman hidup yang negatif cenderung sulit untuk dapat mengatasi hambatan yang muncul dalam hidupnya (Bowman, 2010).

Temuan lainnya adalah bagaimana seorang mahasiswa baru dapat mengelola lingkungannya sehingga mahasiswa dapat merasa nyaman di lingkungan dimana mahasiswa berada dapat turut menentukan kemungkinan seorang mahasiswa baru mengalami gejala gangguan mental pada tahun pertamanya menjadi mahasiswa. Keyakinan bahwa mahasiswa dapat menciptakan lingkungan nyaman untuk dirinya di lingkungan yang baru mengindikasikan penilaian mahasiswa terhadap situasi baru di dunia perkuliahan bukan sebagai hal yang menyulitkan dan menghindarkan mahasiswa dari kecemasan yang seringkali menjadi dasar pada berbagai gangguan mental (Freire et al,
2019). Sebuah penelitian menjelaskan bahwa cara penyelesaian masalah mahasiswa pada saat menghadapi hambatan di dunia perkuliahan yang baru berhubungan erat dengan penyelesaian masalah yang mereka lakukan. Mahasiswa yang memiliki kesejahteraan psikologis tinggi, terutama pada dimensi selfacceptance, environmental mastery, purpose in life, dan personal growth cenderung lebih sering menggunakan tiga strategi penyelesaian masalah yang adaptif yaitu positive reappraisal, support-seeking, dan planning (Freire et al, 2016).

Secara umum hasil penelitian ini sejalan dengan hasil penelitian sebelumnya yang menjelaskan hubungan kesejahteraan psikologis dengan berbagai variabel lain penting dalam latar perkuliahan, misalnya strategi penyelesaian masalah yang adaptif (Freire et al, 2016) efikasi diri (Siddiqui, 2015), performa akademik (Bordbar et al., 2011), burnout (Rehman et al., 2020), dan tingkat stres pada mahasiswa (Aulia \& Panjaitan, 2019). Hal yang baru pada penelitian ini adalah kesejahteraan psikologis digunakan sebagai prediktor munculnya gejala-gejala gangguan psikologis. Penelitian ini memperkuat argumen mengenai pentingnya kesejahteraan psikologis pada mahasiswa tahun pertama, terutama dimensi self-acceptance dan environmental mastery dapat menjadi faktor protektif terhadap indikasi gangguan mental.

Pada dua penelitian lain ditemukan secara konsisten bahwa self-acceptance, 
environmental mastery, dan purpose in life adalah dimensi yang penting bagi mahasiswa baru sebagai sumber daya untuk dapat memenuhi tuntutan dunia perkuliahan (Bowman, 2010; Freire et al, 2016). Perbedaan penemuan penelitian ini dengan dua penelitian lainnya terletak pada dimensi purpose in life, yaitu adanya perasaan memiliki arah dalam hidup, dorongan memiliki tujuan hidup yang jelas, dan memaknakan pengalaman saat ini dan masa lalu sebagai sesuatu yang bermakna. Salah satu penelitian menyebutkan bahwa purpose in life dapat mengalami perubahan apabila pengalaman negatif yang dialami mahasiswa baru mempengaruhi hubungannya dengan para teman baru di tempatnya berkuliah (Bowman, 2010). Sehingga, dapat dikatakan pada penelitian yang menemukan purpose in life dapat memprediksi bagaimana mahasiswa memenuhi tuntutan perkuliahan dipengaruhi pula oleh dimensi positive relation with others. Sedangkan pada penelitian ini, semua dimensi kesejahteraan psikologis, termasuk purpose in life, berhubungan dengan indikasi gangguan psikologis namun tidak semua dimensi menjadi faktor yang dapat memprediksikan munculnya gejala gangguan psikologis. Hal ini mungkin terjadi karena faktor spesifik pada masingmasing dimensi kesejahteraan psikologis, selain self-acceptance dan environmental mastery, secara independen tidak dapat digunakan untuk memprediksikan indikasi gangguan psikologis pada mahasiswa baru. Berdasarkan penelitian sebelumnya, muncul dugaan bahwa relasi dengan teman baru di dunia perkuliahan meskipun berhubungan namun tidak mempengaruhi perasaan keterarahan dalam hidup pada mahasiswa baru.

Penelitian lain mengkategorikan kesejahteraan psikologis menjadi beberapa aspek, yaitu spiritual (purpose in life), sosial (positive relation with others), dan kognitif (autonomy, personal growth, self-acceptance, environmental mastery) (Bornstein et al, 2003; Perez, 2012). Self-acceptance dan environmental mastery dikatakan memiliki komponen kognitif yang kental, yaitu berhubungan dengan bagaimana mahasiswa menyadari kelebihan dan kekurangannya serta bersikap positif terhadap kelebihan dan kekurangannya ini. Sedangkan, environmental mastery berhubungan dengan keyakinan seseorang untuk dapat membuat lingkungan di sekelilingnya memenuhi kebutuhannya. Dua kondisi ini membuat seorang mahasiswa baru yang dihadapkan pada berbagai kesulitan di lingkungan perkuliahan yang baru dapat tetap bersikap optimis bahwa mahasiswa akan dapat mengatasi kesulitan yang mahasiswa hadapi. Jikapun mengalami hambatan, mereka yang memiliki penerimaan diri positifyang tinggi dan keyakinan untuk dapat mengelola lingkungan dapat dengan cepat bangkit dan mencari cara untuk mengatasi kesulitan baik dengan memanfaatkan kelebihan diri dan sumber daya yang ada di lingkungan sehingga tidak membuat mahasiswa terpuruk dan akhirnya memunculkan gejala-gejala gangguan 
psikologis. Pada dasarnya sebagian besar gangguan psikologis yang dicirikan dengan kecemasan merupakan indikasi adanya stressor yang tidak dapat diatasi oleh seseorang. Pada beberapa penelitian kesejahteraan psikologis dikaitkan dengan hardiness (OteroLópez et al, 2014) dan resiliensi (Gonzáleztorres \& Artuch-garde, 2014).

Secara independen, salah satu penjelasan dimensi penerimaan diri sebagai prediktor terhadap indikasi gangguan psikologis dapat digambarkan secara tidak langsung melalui penelitian self-acceptance sebagai moderator antara keyakinan akan kondisi frustrasi yang tidak dapat ditoleransi dengan derajat stres akademis seorang mahasiswa (Jibeen, 2017). Misalnya, mahasiswa yang memiliki keyakinan bahwa mahasiswa akan tidak dapat mengatasi perasaan frustasi apabila tidak berhasil mencapai suatu prestasi yang mahasiswa inginkan ternyata tidak selalu memiliki derajat stress akademik yang tinggi, apabila mahasiswa memiliki pandangan yang positif mengenai diri sendiri. Beberapa intervensi yang ditujukan untuk mahasiswa agar memfokuskan pada penerimaan diri yang positif, mengurangi evaluasi diri yang negatif telah terbukti memiliki dampak terhadap proses transisi dari sekolah ke universitas yang lebih baik dan memiliki perilaku serta emosi yang lebih positif (Dvoøáková et al., 2017; Koydemir \& SunSelýbýk, 2016). Sedangkan, dimensi environmental mastery dapat dikembangkan melalui program yang membuat mahasiswa baru lebih cepat dapat menguasai lingkungan kampus baik fisik maupun sosial (Susanti \& Supradaniati, 2018).

Limitasi penelitian ini adalah metode penelitian yang menggambarkan hanya satu angkatan mahasiswa baru pada satu fakultas sehingga belum dapat melakukan kontrol terhadap kemungkinan variasi yang terkait karakteristik angkatan mahasiswa baru dan karakteristik fakultas. Oleh karena itu, penelitian selanjutnya pada topik ini dapat pula dilakukan dengan menambah variasi angkatan dan fakultas asal mahasiswa baru.

\section{Simpulan}

Penelitian ini bertujuan untuk mendapatkan gambaran mengenai hubungan antara gangguan psikologis dengan kesejahteraan psikologis dan menganalisis dimensi kesejahteraan psikologis yang dapat menjadi faktor protektif bagi mahasiswa agar terhindar dari gangguan psikologis. Berdasarkan temuan dalam penelitian ini dapat disimpulkan bahwa tingkat kesejahteraan psikologis dapat memprediksikan munculnya indikasi gangguan mental pada mahasiswa yang berada pada tahun pertama.

\section{Saran}

Mahasiswa tahun pertama yang memiliki tingkat kesejahteraan psikologis tinggi mampu memanfaatkan sumber daya dalam diri dan di luar diri untuk mengatasi kesulitan yang muncul dalam kehidupan perkuliahannya sehingga 
lebih. Keyakinan bahwa dirinya mampu mengatasi kesulitan menjadi faktor protektif terhadap munculnya gejala gangguan psikologis. Oleh karena itu, intervensi pada mahasiswa tahun pertama sebaiknya ditujukan untuk meningkatkan penerimaan diri yang positif, dan keyakinan untuk dapat mengelola lingkungan agar dapat merasa nyaman. Intervensi ini dapat dilakukan secara preventif oleh pihak institusi pendidikan secara umum dan secara spesifik dilekatkan pada program penerimaan mahasiswa baru pada masingmasing fakultas.

\section{Referensi}

Adlaf, E. M., Gliksman, L., Demers, A., Adlaf, E. M., Gliksman, L., Demers, A., \& Newtontaylor, B. (2010). The prevalence of elevated psychological distress among Canadian undergraduates: Findings from the 1998 Canadian Campus Survey. Journal of American College Health, 50(2), 67-72. https://doi.org/10.1080/ 07448480109596009

Agnafors, S., Barmark, M., \& Sydsjö, G. (2020). Mental health and academic performance: A study on selection and causation effects from childhood to early adulthood. Social Psychiatry and Psychiatric Epidemiology. https:// doi.org/10.1007/s00127-020-01934-5

Aldiabat, K. M., Matani, N. A., \& Navenec, C. L. (2014). Mental health among undergraduate university students: A background paper for administrators, educators and healthcare providers. Universal Journal of Public Health, 2(8), 209-214. https://doi.org/10.13189/ ujph.2014.020801

American Psychiatric Association. (2013). Diagnostic and statistical manual of mental disorders (5th ed.). American
Psychiatric Publishing. https://doi.org/ h ttps://doi.org / 10.1176 / appi.books.9780890425596

Angela, M. L., Hurtado, S., Bowman, N., \& Oseguera, L. (2008). Extending notions of campus climate and diversity to students' transition to college. The Review of Higher Education, 31(3), 257-285. https://doi.org/10.1353/rhe.2008.0011

Angelidis, A., Solis, E., Lautenbach, F., Van Der, W., \& Putman, P. (2019). I'm going to fail! Acute cognitive performance anxiety increases threat-interference and impairs WM performance. PLOS ONE, 14(2), 1-25. https://doi.org/10.17605/ OSF.IO/6KBC8

Auerbach, R. P., Alonso, J., Axinn, W. G., Cuijpers, P., Ebert, D. D., Green, J. G., Hwang, I., Kessler, R. C., Liu, H., Mortier, P., Nock, M. K., Pinder-Amaker, S., Sampson, N. A., Aguilar-Gaxiola, S., Al-Hamzawi, A., Andrade, L. H., Benjet, C., Caldas-deAlmeida, J. M., Demyttenaere, K., Florescu, S., ..., \& Bruffaerts, R. (2016). Mental disorders among college students in the World Health Organization World Mental Health Surveys. Psychological Medicine, 46(14), 2955-2970. https://doi.org/ $10.1017 / \mathrm{S} 0033291716001665$

Auerbach, R. P., Mortier, P., Bruffaerts, R., Alonso, J., Benjet, C., Cuijpers, P., Demyttenaere, K., Ebert, D. D., Green, J. G., Hasking, P., Murray, E., Nock, M. K., Pinder-Amaker, S., Sampson, N. A., Stein, D. J., Vilagut, G., Zaslavsky, A. M., \& Kessler, R. C. (2018). WHO world mental health surveys international college student project: Prevalence and distribution of mental disorders. Journal of Abnormal Psychology, 127(7), 623638. https://doi.org/10.1037/ abn0000362

Aulia, S., \& Panjaitan, R. U. (2019). Psychological well-being and level of stress among the last year college students. Jurnal Keperawatan Jiwa, 7(2), 127-134. https://doi.org/10.26714/ jkj.7.2.2019.127-134 
Baik, C., Larcombe, W., \& Brooker, A. (2019). How universities can enhance student mental wellbeing: The student perspective. Higher Education Research and Development, 38(4), 674-687. https://doi.org/10.1080/ 07294360.2019 .1576596

Beiter, R., Nash, R., Mccrady, M., Rhoades, D., Linscomb, M., Clarahan, M., \& Sammut, S. (2015). The prevalence and correlates of depression, anxiety, and stress in a sample of college students. Journal of Affective Disorders, 173, 90-96. https:// doi.org/10.1016/j.jad.2014.10.054

Bewick, B., Koutsopoulou, G., Miles, J., \& Barkham, M. (2010). Changes in undergraduate students ' psychological well-being as they progress through university. Studies In Higher Education, 35(6), 633-645. https://doi.org/ 10.1080/03075070903216643

Bordbar, F. T., Nikkar, M., Yazdani, F., \& Alipoor, A. (2011). Comparing the psychological well-being level of the students of Shiraz Payame Noor University in view of demographic and academic performance variables. Procedia - Social and Behavioral Sciences, 29, 663-669. https:/ /doi.org/10.1016/j.sbspro.2011.11.290

Bowman, N. A. (2010). The development of psychological well-being among firstyear college students. Journal of College Student Development, 51(2), 180-200. https://doi.org/10.1353/csd.0.0118

Browne, J., Penn, D., Kalos, P., Mueser, K., Estroff, S., Bruenette, M., ... ., \& Kane, J. (2017). Psychological well-being and mental health recovery in the NIMH RAISE early treatment program. Schizophrenia Research, 185, 167-172. https://doi.org/ 10.1016/j.schres.2016.11.032

Bruffaerts, R., Mortier, P., Kiekens, G., Auerbach, R. P., Cuijpers, P., Demyttenaere, K., Green, J. G., Nock, M. K., \& Kessler, R. C. (2018). Mental health problems in college freshmen: Prevalence and academic functioning. Journal of Affective Disorders, 225, 97-103. https://doi.org/ 10.1016/j.jad.2017.07.044
Chow, H. P. H. (2007). Psychological well-being and scholastic achievement among university students in a Canadian Prairie City. Social Psychology Education, 10(4), 483-493. https://doi.org/10.1007/ s11218-007-9026-y

Cooke, R., Bewick, B. M., Barkham, M., Bradley, M., \& Audin, K. (2006). Measuring, monitoring and managing the psychological well-being of first year university students. British Journal of Guidance \& Counselling, 34(4), 37-41. h t tp s: / / doi.org / 10.1080 / 03069880600942624

Dvoøáková, K., Kishida, M., Li, J., Elavsky, S., Broderick, P. C., Mark, R., \& Greenberg, M. T. (2017). Promoting healthy transition to college through mindfulness training with 1st year college students: Pilot randomized controlled trial. Journal of American College Health, 65(4), 259267. https://doi.org/10.1080/ 07448481.2017 .1278605

Freire, C., Del, M., Ferradás, M., Valle, A., Núñez, J. C., \& Vallejo, G. (2016). Profiles of psychological well-being and coping strategies among university students. Frontiers in Psychology, 7(October), 111. https://doi.org/10.3389/ fpsyg.2016.01554

Freire, C., Ferradás, M. D. M., Núñez, J. C., Valle, A., \& Vallejo, G. (2019). Eudaimonic wellbeing and coping with stress in university students: The mediating/ moderating role of self-efficacy. International Journal of Environmental Research and Public Health, 16(1). h ttp s: / / doi.org/10.3390/ ijerph16010048

Gallagher, R. P., Gill, A. M., \& Sysko, H. B. (2000). National survey of counseling center directors $2000 . \quad \mathrm{http}: / / \mathrm{d}$ scholarship.pittedu/id/eprint/28160

González-torres, M. C., \& Artuch-garde, R. (2014). Resilience and coping strategy profiles at university: Contextual and demographic variables. Journal of Research in Educational Psychology, 
12(3), 621-648. https://doi.org/ 10.14204/ejrep.34.14032

Hjorth, C. F., Bilgrav, L., \& Frandsen, L. S. et al. (2016). Mental health and school dropout across educational levels and genders: A 4.8-year follow-up study. BMC Public Health, 16(976), 1-12. https://doi.org/ 10.1186/s12889-016-3622-8

Holmes, A., \& Silvestri, R. (2016). Rates of mental illness and associated academic impacts in Ontario's College Students. Canadian Journal of School Psychology, 31(1), 2746. https://doi.org/10.1177/ 0829573515601396

Huppert, F. A. (2009). Psychological well-being: Evidence regarding its causes and consequences. Applied Psychology: Healty and Well-Being, 1(2), 137-164. https://doi.org/10.1111/j.17580854.2009.01008.x

Hurtado, S., \& Carter, D. F. (1997). Effects of college transition and perceptions of the campus racial climate on Latino College students' sense of belonging. Sociology of Education, 70(4), 324-345. https:// doi.org/10.2307/2673270

Jackson, M., Student, D., \& Ray, S. (2013). International students in the U.S.: Social and psychological adjustment Journal of International Students, 3(1), 17-28. https://www.ojed.org/index.php/jis/ article/view/515

Jibeen, T. (2017). Unconditional self-acceptance and self-esteem in relation to frustration intolerance beliefs and psychological distress. Journal of Rational - Emotive and Cognitive - Behavior Therapy, 35(2), 207-221. https://doi.org/10.1007/ s10942-016-0251-1

Kitzrow, M. A. (2009). The mental health needs of today's college students / : Challenges and recommendations. NASPA Journal, 46(4), 167-181. https://doi.org/ 10.2202/1949-6605.5037

Koydemir, S., \& Sun-Selýbýk, Z. E. (2016). Wellbeing on campus: Testing the effectiveness of an online strengthsbased intervention for first year college students. British Journal of Guidance and Counselling, 44(4), 434-446. https:// d o i . o r g / 10 . 1080 / 03069885.2015.1110562

Kumaraswamy, N. (2013). Academic stress, anxiety and depression among college students - a brief review introduction. International Review of Social Sciences and Humanities, 5(1), 135-143.

Lewis, G. J., Kanai, R., Rees, G., \& Bates, T. C. (2013). Neural correlates of the "good life": eudaimonic well-being is associated with insular cortex volume. Social Cognitive and Affective Neuroscience, 9(5), 615-618. https://doi.org/10.1093/ scan/nst032

Liu, Q., Shono, M., \& Kitamura, T. (2009). Psychological well-being, depression, and anxiety in Japanese University students. Depression and Anxiety, 26(8), 99-105. https://doi.org/10.1002/da.20455

Mahomed, N. J. B., Johari, K. S. K., \& Mahmud, M. I. (2019). Coping strategies and psychological well-being of guidance and counselling teachers in schools. Creative Education, 10(12), 3028-3040. https:// doi.org/10.4236/ce.2019.1012227

Mendoza-denton, R., Downey, G., Purdie, V. J., Davis, A., \& Pietrzak, J. (2014). Sensitivity to status-based rejection/: Implications for african American students' college cxperience. Journal of Personality and Social Psychology, 83(4), 896-918. http s://doi.org/10.1037 / 0022 3514.83.4.896

Otero-López, J. M., Villardefrancos, E., Castro, C., \& Santiago, M. J. (2014). Stress, positive personal variables and burnout/: A path analytic approach José Manuel OteroLópez, Estíbaliz Villardefrancos, Cristina. European Journal of Education and Psychology, 7(2), 95-106. https:// doi.org/10.30552/ejep.v7i2.105

Pascoe, M. C., Hetrick, S. E., \& Parker, A. G. (2020). The impact of stress on students 
in secondary school and higher education. International Journal of Adolescence and Youth, 25(1), 104-112. h t tp s: / / do i.org / 10.1080 / 02673843.2019 .1596823

Pedrelli, P., Nyer, M., Yeung, A., Zulauf, C., \& Wilens, T. (2015). College students: Mental health problems and treatment considerations. Academic Psychiatry, 39(5), 503-511. https://doi.org/ 10.1007/s40596-014-0205-9

Perez, J. A. (2012). Gender difference in psychological well-being among Filipino College student samples. International Journal of Humanities and Social Science, 2(13), 84-93. https://doi.org/10.25215/ 0204.040

Rehman, A. U., Bhuttah, T. M., \& You, X. (2020). Linking burnout to psychological wellbeing: The mediating role of social support and learning motivation. Psychology Research and Behavior Management, 13, 545-554. https:// doi.org/10.2147/PRBM.S250961

Roberts, R., Golding, J., Towell, T., Reid, S., \& Woodford, S. (2000). Mental and physical health in students: The role of economic circumstances. British Journal of Health Psychology, 5(3), 289-297. https:// doi.org/10.1348/135910700168928

Rose, G., Khaw, K.-T., \& Marmot, M. (2008). Rose's strategy of preventive medicine: The complete original text. Oxford University Press. https://doi.org/ $10.1093 /$ a c p r o f: o s o / 9780192630971.001.0001

Ryff, C., \& Keyes, C. (1995). The structure of psychological well-being revisited. Journal of Personality and Social Psychology, 69(4), 719-727. https:// doi.org/10.1037/0022-3514.69.4.719

Ryff, C D. (2018). Eudaimonic well-being, inequality, and health: Recent findings and future directions. Int Rev Econ, 64(2), 1-19. https://doi.org/10.1007/ s12232-017-0277-4
Ryff, C D, \& Singer, B. H. (2008). Know thyself and become what you are: A eudaimonic approach to psychological well-being. Journal of Happiness Studies, 9(1), 1339. https://doi.org/10.1007/s10902006-9019-0

Ryff, Carol D. (1989). Happiness is everything, or is it? Explorations on the meaning of psychological well-being. Journal of Personality and Social Psychology, 57(6), 1069-1081. https://doi.org/10.1037/ 0022-3514.57.6.1069

Ryff, Carol D. (2014). Psychological well-being revisited/: Advances in the science and practice of Eudaimonia. Psychotherapy and Psychosomatics, 83(1), 10-28. https://doi.org/10.1159/000353263

Saleem, S., \& Mahmood, Z. (2013). Mental health problems in university students: A prevalence study. FWU Journal of Social Sciences, 7(2), 124-130. https:// www.researchgate.net/publication/ 310596848_Mental_Health_Problems_in_ University_Students_A_prevalence_study

Saleh, D., Camart, N., \& Romo, L. (2017). Predictors of stress in college students. Frontiers in Psychology, 8, 1-8. https:// doi.org/10.3389/fpsyg.2017.00019

Sari, A. N., Oktarlina, R. Z., \& Septa, T. (2017). Masalah kesehatan jiwa pada mahasiswa kedokteran. Medula, 7(4), 82-87. https:/ /juke.kedokteran.unila.ac.id/index.php/ medula/article/view/1694

Schunk, D. H., \& Pajares, F. (2002). Chapter 1 The development of academic selfefficacy. In A. Wigfield \& J. S. B. T.-D. of A. M. Eccles (Eds.), Educational Psychology (pp. 15-31). Academic Press. https:// doi.org/10.1016/B978-012750053-9/ 50003-6

Schwitzer, A. M., Moss, C. B., Pribesh, S. L., St. John, D. J., Burnett, D. D., Thompson, L. H., \& Foss, J. J. (2018). Students with mental health needs: College counseling experiences and academic success. Journal of College Student Development, 
59(1), 3-20. https://doi.org/10.1353/ csd.2018.0001

Shiels, C., Gabbay, M., \& Exley, D. (2008). Psychological distress in students registered at a university-based general practice. Primary Care and Community Psychiatry, 13(1), 9-18. https://doi.org/ 10.1080/17468840701791418

Siddiqui, S. (2015). Impact of self-efficacy on psychological well-being among undergraduate students. The International Journal of Indian Psychology, 2(3). https://doi.org/ $10.25215 / 0203.040$

Sreeramareddy, C. T., Shankar, P. R., Binu, V., Mukhopadhyay, C., Ray, B., \& Menezes, R. G (2007). Psychological morbidity, sources of stress and coping strategies among undergraduate medical students of Nepal. BMC Medical Education, 7(1), 1-8. https:/ /doi.org/10.1186/1472-6920-7-26

Stewart-brown, S., Evans, J., Patterson, J., Petersen, S., Doll, H., Balding, J., \& Regis, D. (2000). The health of students in institutes of higher education: An important and neglected public health problem? Journal of Public Health Medicine, 22(4), 492-499. https:// doi.org/10.1093/pubmed/22.4.492

Storrie, K., Ahern, K., \& Tuckett, A. (2010). A systematic review: Students with mental health problems-A growing problem. International Journal of Nursing Practice, 16, 1-6. https://doi.org/ 10.1111/j.1440-172X.2009.01813.X

Suardi, A., Sotgiu, I., Costa, T., Cauda, F., \& Rusconi, M. (2016). The neural correlates of happiness: A review of PET and fMRI studies using autobiographical recall methods. Cognitive, Affective and Behavioral Neuroscience, 16(3), 383392. https://doi.org/10.3758/s13415016-0414-7

Susanti, S. S., \& Supradaniati, S. S. (2018). Psychological well-being among Indonesian students studying abroad. Idea Nursing Journal, 9(2), 50-54. http://
jurnal.unsyiah.ac.id/INJ/article/view/ 14028

Tang, Y. Y., Tang, R., \& Gross, J. J. (2019). Promoting psychological well-being through an evidence-based mindfulness training program. Frontiers in Human Neuroscience, 13, 1-5. https://doi.org/ 10.3389/fnhum.2019.00237

Van Reekum, C., Urry, H. L., Johnstone, T., Thurow, M. E., Frye, C. J., Jackson, C. A., Schaefer, H. S., Alexander, Andrew L. Davidson, R. J., \& Abstract. (2007). Individual differences in amygdala and ventromedial prefrontal cortex activity are associated with evaluation speed and psychological well-being. Journal of Cognitive Neuroscience, 19(2), 237-248. h ttp s: / / doi.org/10.1162/ jocn.2007.19.2.237

van Rooij, E. C. M., Jansen, E. P. W. A., \& van de Grift, W. J. C. M. (2018). First-year university students' academic success: The importance of academic adjustment. European Journal of Psychology of Education, 33(4), 749-767. https:// doi.org/10.1007/s10212-017-0347-8

VanderLind, R. (2017). Effects of mental health on student learning. The Learning Assistance Review, 22(2), 39-58. https:/ /eric.ed.gov/?id=EJ1154566

Vidiawati, D., Iskandar, S., \& Agustian, D. (2017). Masalah kesehatan jiwa pada mahasiswa baru di sebuah universitas di Jakarta mental disorder of freshmen students of primary health University Clinic. EJournal Kesehatan Indonesia, 5(1), 2733. https://doi.org/10.23886/ ejki.5.7399.27-33

Weiss, L. A., Westerhof, G. J., \& Bohlmeijer, E. T. (2016). Can we increase psychological well-being? The effects of interventions on psychological well-being: A metaanalysis of randomized controlled trials. PLOS ONE, 11(6), 1-16. https://doi.org/ 10.1371/journalpone.0158092

World Health Organization. (1994). Self Report Questionnaire (SRQ-20). https:// 
apps.who.int/iris/bitstream/handle/ $\begin{array}{llllllllllll}1 & 0 & 6 & 6 & 5 & / & 6 & 1 & 1 & 1 & 3 & /\end{array}$ WHO_MNH_PSF_94.8.pdf;jsessionid= F4B958832D1A01032DD35BA02FCE6E7C? sequence $=1$

Xiao, H., Carney, D. M., Youn, S. J., Janis, R. A., Castonguay, L. G., Hayes, J. A., \& Locke, B. D. (2017). Are we in crisis? National mental health and treatment trends in college counseling centers. Psychological Services, 14(4), 407415. https://doi.org/10.1037/ ser0000130

Yasin, A., \& Dzulkifli, M. (2010). The relationship between social support and psychological problems among students. International Journal of Business and Social Science, 1(3), 110-116. https:// www.researchgate.net/publication/ 228609959 _The_Relationship_
between_Social_Support_and_ Psychological_Problems_among_Students

Yousefi, F., Redzuan, M., \& Juhari, R. B. (2016). Study of comparison among information processing theory, interference model of test anxiety and Beck's Cognitive Theory of depression with regard to their relationship with academic achievement. Avicenna J Neuro Psycho Physiology, 3(4), 94-100. https://doi.org/10.5812/ ajnpp.58803.Review

Zajacova, A., Lynch, S. M., \& Espenshade, T. J. (2005). Self-efficacy, stress, and academic success in college. Research in Higher Education, 46(6), 677-706. https:// doi.org/10.1007/s11162-004-4139-z

Received 3 September 2020 Revised 7 October 2020 Accepted 5 January 2021 
